\title{
CORTE SUPREMA Y RECURSO EXTRAORDINARIO: ALGUNAS CONSIDERACIONES DE CARA A LA REFORMA PROCESAL CIVIL
}

\author{
Supreme Court of Justice and extraordinary appeal: some considerations in \\ light of the chilean civil procedure reform
}

Pablo Andrés Becerra Poblete*

Resumen: El Proyecto de Nuevo Código Procesal Civil propone a debate una posición específica acerca del rol que ha de cumplir la Corte Suprema en materia recursiva de cara a la Reforma Procesal Civil. Sin embargo, no parece haber claridad acerca de cuál es el rol que en el contexto más amplio del sistema constitucional debe cumplir la Corte. De ese desajuste surgen interrogantes relevantes para la democracia y el rol que como institucionalidad democrática cabe a los tribunales de justicia en el contexto constitucional. La visibilización de la tensión entre las exigencias constitucionales de una democracia moderna en lo relativo al sistema judicial y la configuración del recurso extraordinario es el objetivo del presente trabajo, proponiendo cinco tópicos para la reflexión legislativa futura.

Palabras clave: Corte Suprema - Reforma Procesal Civil - Derechos Fundamentales - Debido Proceso - Recurso Extraordinario.

\begin{abstract}
The bill of the new civil procedure code proposes an specific position concerning the role that the Supreme Court should play in light of the appeals system upcoming chilean civil procedure reform. However, it seems that there is not much clarity on which role the Court should play in the constitutional system's broader context. From this lack of adjustment, several questions arise, which are relevant for democracy and for the role that courts should play as democratic institutions in the constitutional context. The purpose of this work is to highlight the tensions between a modern democracy's constitutional requirements regarding the judicial system and the legal configuration of the "recurso extraordinario" (extraordinary appeal), in light of five proposed topics for future legislative discussion.
\end{abstract}

Keywords: Supreme Court - Civil Procedure Reform - Fundamental Rights - Due Process - Extraordinary Appeal.

\footnotetext{
*Abogado. Licenciado en Ciencias Jurídicas y Sociales por la Universidad de Chile. Alumno del programa de Magíster en Derecho, mención Derecho Público, de la Universidad de Chile. Correo electrónico: pbecerrap@gmail.com
}

Este artículo fue recibido el 17 de octubre del año 2012, siendo aprobada su publicación con fecha 20 de diciembre de 2012 . 
Becerra - Corte Suprema y recurso extraordinario: algunas consideraciones...

\section{Introducción}

Luego de siglos de mantener prácticamente inalterado el sistema de justicia nacional, en los últimos años hemos emprendido como país una serie de reformas tendientes a adecuar nuestra institucionalidad al ideario de Estado Democrático de Derecho. Ello comenzó con la discusión de la Reforma Procesal Penal cuya génesis se remonta a la década de los noventa y cuya implementación culminaría con su puesta en marcha en la Región Metropolitana en el año 2005; pasando por la necesaria modernización a la justicia de familia mediante la implementación de nuevos tribunales y procedimientos de familia; y culminando más recientemente con la creación de los nuevos tribunales laborales, tribunales tributarios y aduaneros, y los tribunales ambientales.

En marzo de 2012, una de las más importantes reformas a nuestro sistema jurídico se puso en marcha, con la presentación al Congreso de un proyecto de Nuevo Código Procesal Civil (en adelante NCPC), que constituye la primera piedra de un número de ejes estructurales que, en su conjunto, materializarán la denominada Reforma Procesal Civil. Uno de estos ejes estructurales en torno al cual gira la reforma, y que ha permanecido básicamente intocado a lo largo de toda nuestra historia republicana, viene dado precisamente por los tribunales superiores de justicia y su rol en el sistema judicial; y especialmente, el de la Corte Suprema de Justicia. Más concretamente, aunque la regulación orgánica no es abordada en el proyecto de NCPC presentado en marzo de 2012, este proyecto ya adelanta algunas propuestas que impactan sobre el rol de la Corte Suprema en el sistema judicial, confiriéndole la función de tribunal de unificación de jurisprudencia a través de un mecanismo de selección de casos que ella estime de interés general, calificado este interés por la circunstancia de existir afectación de garantías fundamentales, o bien por involucrar la necesidad de pronunciarse sobre una doctrina jurisprudencial divergente. Es decir, el NCPC propone a debate una posición específica acerca del rol que ha de cumplir la Corte Suprema en materia jurisdiccional de cara a la Reforma. A este respecto, el mensaje con el cual se despachó el proyecto de ley de $\mathrm{NCPC}^{1}$ resulta bastante elocuente, identificando como eje central del nuevo Código el nuevo sistema recursivo propuesto y el rol de la Corte Suprema asociado al mismo. ${ }^{2}$

De ese modo, es dable afirmar que el proceso puesto en marcha con la primera piedra de la Reforma Procesal Civil -el NCPC- supone el comienzo de importantes transformaciones en lo que respecta al rol de la Corte Suprema. Bajo esa premisa, la cuestión que pretende abordarse en las próximas líneas, aunque sea someramente, apunta a verificar si la específica configuración recursiva escogida en el proyecto de NCPC con el denominado "recurso extraordinario" resulta satisfactoria a la luz de las exigencias y desafíos que plantea un Estado democrático

\footnotetext{
${ }^{1}$ Boletín 8197-2007, presentado al Congreso con fecha 13 de marzo de 2012.

${ }^{2}$ Mensaje NCPC, IV.5.
} 
de derecho. El cuestionamiento nos parece pertinente puesto que actualmente la Corte cumple una pluralidad de roles en nuestro sistema jurídico, pero que no han sido tratados de manera sistemática e integral por el legislador, ni abordados en profundidad sino en forma parcelada por la literatura jurídica, de modo que no parece haber claridad en el debate nacional sobre cuál es la función que una (nuestra) Corte Suprema ha de cumplir en una sociedad democrática moderna y, específicamente, cómo incide la configuración recursiva en el adecuado cumplimiento del rol que se asigne al máximo tribunal.

Consecuentemente, se hace necesario reflexionar acerca de cuál es el sentido y diseño "original" de la Corte - de dónde viene la Corte Suprema- para luego poder visualizar críticamente su sistema recursivo y ofrecer criterios prospectivos armónicos con los principios en torno a los cuales deben estructurarse reformas futuras en materia de recursos -hacia dónde va la Corte Suprema-.

Para ello, luego de esta introducción, se intentará una breve descripción del diseño institucional de la Corte Suprema $\left(\mathrm{N}^{\circ} 2\right)$, describiendo a continuación lo que estimamos un defecto central en dicho diseño, esto es, que arriesga impactar adversamente sobre la independencia de cada sentenciador al enfrentar un caso $\left(\mathrm{N}^{\circ}\right.$ 3). Enseguida, reflexionamos acerca de cómo la jurisdicción es una actividad definida de modo muy central por la independencia del órgano decisorio $\left(\mathrm{N}^{\circ} 4\right)$, para finalizar con cinco tópicos que emergen a partir de estas reflexiones en relación con el régimen recursivo propuesto como competencia de la Corte Suprema en el proyecto de NCPC.

\section{Diseño originario de la Corte Suprema}

La primera cuestión que debe consignarse es que el diseño estructural y rol de la Corte Suprema chilena es uno que puede trazarse desde épocas coloniales a nuestros días básicamente sin modificaciones. La judicatura tiene una larga tradición histórica, remontándose los antecedentes de la Corte Suprema a la Real Audiencia, con asiento en la ciudad de Concepción. ${ }^{3}$ Ese diseño original, basado en la idea de órgano de gobierno judicial en la cúspide de una institución verticalmente jerarquizada, es uno sobre el cual se han introducido algunas reformas que, aunque importantes, no innovan sobre ese diseño básico originario. A lo largo de los años se le han sumado o restado algunas competencias jurisdiccionales, variado su número de ministros y funcionamiento en pleno o salas; pero su diseño institucional y rol como cabeza de un "Poder Judicial" ha permanecido básicamente inalterado. Quizás la reforma más importante de la

\footnotetext{
${ }^{3}$ Navarro Beltrán, Enrique: "Notas sobre el rol de la Corte Suprema en Chile", Expansiva, 2007, disponible en: http://www.expansiva.cl/media/en_foco/documentos/14112007103307.pdf. [fecha de consulta: 13.09.12].
} 
Becerra - Corte Suprema y recurso extraordinario: algunas consideraciones...

última década consistió en remover su competencia sobre el control de constitucionalidad de la ley, para radicarla en el Tribunal Constitucional mediante las reformas introducidas por la Ley $\mathrm{N}^{\circ}$ 20.050; pero ello, no obstante su trascendencia para la vida política y jurídica nacional, importa apenas alterar parcialmente el catálogo de competencias jurisdiccionales de la Corte Suprema, sin tocar su diseño fundamental como cabeza jerárquica de un Poder Judicial.

$\mathrm{Y}$ es que, como anota un autor, el diseño institucional actual de la Corte no presenta mayores diferencias con respecto a la Corte Suprema del siglo XIX y el sistema judicial en que ella estaba inserta, siendo tal sistema tributario de una teoría política de cuño monárquico y pre republicano: un juez de primera instancia, superior del servicio administrativo de justicia que representa cada tribunal; una Corte de Apelaciones, superior jerárquico del anterior a quien se encomienda la revisión de las decisiones del primero, dotada de mayores atribuciones administrativas y funcionarias, y que participa en el proceso de generación de jueces; para culminar en la Corte Suprema como cabeza de un Poder Judicial, superior administrativa de todo el sistema y estación terminal de la carrera judicial chilena. ${ }^{4}$

Resulta evidente que en su diseño institucional originario estuvo marcadamente presente la idea de órgano de gobierno de modo tal que en territorio indiano viniera a suplir el rol que cumplía el Consejo de Indias; consejo que reunía múltiples funciones, una de las cuales era ejercer funciones jurisdiccionales, pero que detentaba también importantes funciones legislativas y de administración o ejecutivas. $^{5}$

Lo que cabe destacar entonces es que la institucionalidad judicial indiana era una concebida como parte de un poder absoluto proveniente del soberano, el cual era delegado en funcionarios inferiores para una más eficaz administración del poder, quienes debían ejercerlo con estricta sujeción al marco e instrucciones del superior, como verdaderos comisarios; dándose tal delegación en el marco de una estructura jerárquica en cuyo vértice superior estaba el soberano. Y ese diseño, esa lógica institucional verticalizada en cuyo vértice se encuentra el soberano, informa la estructura de la Corte y el sistema en que ella se inserta hasta el día de hoy. Ello es particularmente notorio en la estructura recursiva para ante los tribunales superiores, que contempla el efecto "devolutivo" de competencia hacia el tribunal superior, es decir, el "poder" vuelve al vértice del cual emana, y con el cual fue investido temporalmente para resolver la contienda sometida a su cognición. Aunque en franco retroceso, esta lógica vertical, de superior-inferior, se apreciaba de forma notoria también en la institución de la consulta, una revisión obligatoria

\footnotetext{
4 Tavolari Oliveros, Raúl: "Reflexiones sobre la Corte Suprema chilena," en El papel de los tribunales superiores, Rubinzal-Culzoni, 1a ed., Santa Fe, 2006, pp. 471-472.

${ }^{5}$ Vid. Carocca Pérez, Alex: "La Corte Suprema y sus competencias en Chile. Reflexiones sobre las funciones de la Corte Suprema", Ius Et Praxis (U. De Talca) 1, 1998, p. 194.
} 
de la decisión del inferior, la cual ha ido perdiendo terreno, conservándose dentro del actual Código de Procedimiento Civil apenas para los juicios de hacienda. ${ }^{6}$

Bajo este prisma, que concibe a la función jurisdiccional como una partícula o elemento de un poder absoluto, el sentido de la Corte Suprema es uno de órgano de auténtico gobierno judicial con facultades omnímodas, para reemplazar al antiguo Poder Real. ${ }^{7}$ En esta línea institucional, es sólo lógico que se reúnan en la Corte una serie de funciones de gobierno junto con la función jurisdiccional: facultades no sólo para revisar las decisiones de sus inferiores - en la forma prescrita por la ley-, sino también para ejercer facultades disciplinarias sobre los integrantes de la institucionalidad judicial y asumir procesos decisorios sobre la administración de los recursos con que cuenta el sistema judicial en su conjunto.

\section{La potestad disciplinaria: impacto sobre la independencia interna}

En la sección anterior expresamos que el diseño de la Corte corresponde al de un órgano de auténtico gobierno judicial, que reúne una serie de funciones en la cúspide de una institucionalidad verticalizada. Tenemos entonces una Corte Suprema premunida de potentes facultades disciplinarias tanto respecto de los jueces de letras, ${ }^{8}$ jueces de garantía, jueces de tribunal oral en lo penal, ${ }^{10}$ miembros de las Cortes de Apelaciones, ${ }^{11}$ como respecto de los integrantes de la propia Corte Suprema. ${ }^{12}$ Ello es consistente con un órgano concebido como superior jerárquico de una institucionalidad subordinada, punto en el cual se aprecia una línea de continuidad en el tiempo, pues ya desde la Constitución de 1823 se reconoce explícitamente a la Corte Suprema la facultad de ejercer la superintendencia directiva, correccional, consultiva y económica sobre todos los tribunales y juzgados de la Nación ${ }^{13}$-función de gobierno que otrora correspondiera a la Audiencia de Concepción- lo que pasaría básicamente en los mismos términos a la Ley de Organización de los Tribunales de 1875, que regularía con mayor detalle tales facultades. Concretamente, esta última ley de 1875 confirió a la Corte la potestad para que pudiera "siempre que lo juzgare conveniente a la buena administración de justicia, corregir por sí las faltas y abusos que cualquiera jueces y funcionarios del orden judicial cometieren en el desempeño de su ministerio". ${ }^{14} \mathrm{Y}$

\footnotetext{
${ }^{6}$ Art. 751 CPC.

7 Carocca Pérez, Alex: "La Corte Suprema...”, p. 197.

${ }^{8}$ Artículos 230 a 532 COT.

${ }^{9}$ Artículo 71 CPP.

10 Artículos 292 a 294 COT.

11 Artículos 535, 537, 538 y 542 COT.

12 Artículos 540 a 542 COT.

13 Art. 143 CPR 1823.

14 Art. 109 Ley de Organización y Atribuciones de los Tribunales 1875.
} 
Becerra - Corte Suprema y recurso extraordinario: algunas consideraciones...

a su turno, esta última norma pasó sin mayores alteraciones en su redacción a nuestro actual Código Orgánico de Tribunales bajo su artículo $541 .{ }^{15}$

Sin embargo, ya desde una primera revisión de la normativa que estructura las potestades correccionales se advierte que éstas no "dialogan" en forma apropiada con otras potestades conferidas a la Corte. En tal sentido, de particular notoriedad resulta el impacto adverso sobre la independencia de los jueces en el ejercicio de la función jurisdiccional que sus decisiones sean revisables por quien está llamado, al mismo tiempo, a ejercer potestades disciplinarias (y calificarlos, decidiendo sobre su carrera): en tal configuración, el incentivo está puesto en conformarse a los criterios del superior jerárquico, más que en el mérito en derecho del caso concreto. Tal y como advierte un grupo de jueces en respuesta a una propuesta de una senadora de la República, el principio jerárquico y el argumento de autoridad, consustanciales a la estructura organizacional esencialmente monárquica y pre republicana del Poder Judicial nacional, adquieren un protagonismo difícilmente compatible con la fundamentación de las decisiones de los órganos jurisdiccionales y la transparencia que reclama un Estado Democrático de Derecho. ${ }^{16}$

Entonces, el análisis de las potestades disciplinarias no puede analizarse sin visualizar, al mismo tiempo, la estructura de carrera funcionaria por ascensos que tiene por eje central, también, a la Corte en tanto entidad de gobierno judicial; y cómo esta particular estructura impacta sobre la independencia de cada juez.

Como explica Zapata, "los jueces ingresan en los niveles más bajos y son ascendidos paulatinamente, ascenso que es definido por decisiones en las que intervienen otros jueces aludidos como superiores, por integrar los niveles más altos. La columna vertebral de un sistema de este tipo es el régimen de nombramientos y promociones, el que idealmente debe contemplar un modelo por concursos transparente y competitivo que privilegie los méritos objetivamente verificables. En su ausencia, en nuestra judicatura, el nombramiento y ascenso es definido por reglas de antigüedad más un lobby desplegado en un marco de completa discrecionalidad". ${ }^{17}$

El sistema disciplinario persigue hacer a los jueces responsables por infracciones derivadas de deberes establecidos en cláusulas generales

\footnotetext{
15 "La Corte Suprema puede, además, siempre que lo juzgare conveniente a la buena administración de justicia, corregir por si las faltas o abusos que cualesquiera jueces o funcionarios del orden judicial cometieren en el desempeño de su ministerio, usando para ello de las facultades discrecionales que corresponden a las Cortes de Apelaciones con arreglo a los artículos 536 y 537”' (art. 541 inciso $2^{\circ}$ COT).

16 Bluck, Nancy et al: "Sobre la propuesta de Soledad Alvear en El Mostrador," Jurisdicción y Democracia, disponible en:

http://jurisdiccionydemocracia.cl/?s=Soledad+Alvear [fecha de consulta: 02.09.12]

17 Zapata, María Francisca: "Sin temor ni esperanza. Condiciones estructurales de una eficiente juridificación de las expectativas normativas", Revista de Estudios de la Justicia No 10, 2008, p. 256.
} 
REJ - Revista de Estudios de la Justicia - No 17 - Año 2012

amplias o derechamente abiertas, cuyo contenido será acotado, conforme a la libre interpretación del juzgador del caso. Esta situación se ve agravada, con la ausencia de una graduación de las sanciones, en relación con cada conducta activa u omisiva no deseada, conforme la mayor o menor gravedad de la falta. Si bien el procedimiento ha sido objeto de recientes modificaciones, que en general mejoran el sustrato de garantías para el enjuiciado, está lejos de constituir un régimen capaz de satisfacer las exigencias de un estatuto de esta importancia que, de suyo, debe lograr hacer compatibles la imposición de la disciplina y el respeto de la inamovilidad, soporte básico de la independencia judicial. ${ }^{18}$

Ambos institutos - disciplina y calificación- confluyen en la misma cúspide de la pirámide judicial, que revisa las resoluciones impugnadas de quienes, al mismo tiempo, disciplina y califica; y que lo hace sobre la base de amplios espacios de discrecionalidad. Luego, la independencia interna del juez queda en entredicho si con ocasión del ejercicio de la función jurisdiccional puede arriesgar su carrera y futuro. Si ello ocurre, existe la posibilidad de que los criterios de adjudicación responden en todo o parte a razones funcionales para permanecer o promover la propia carrera; si ello ocurre, corremos el riesgo de que los fundamentos de las decisiones judiciales ya no correspondan a razonamientos jurídicos.

\section{La potestad jurisdiccional: jurisdicción e independencia}

La reunión de las potestades descritas en una misma entidad, bajo la forma en que se encuentran configuradas en Chile, pone en riesgo la independencia judicial; y, siendo la jurisdicción una función estatal caracterizada por la independencia judicial, el diseño institucional compromete la mismísima función que está llamado a cumplir.

Sostener que independencia e imparcialidad son atributos inherentes a la potestad jurisdiccional es lugar común en la ciencia jurídica, puesto que lo determinante de esta función para quien es llamado a ejercerla, es la existencia de un especial ámbito decisorio dentro del cual quien la ejerce -el juez- está llamado a razonar sobre reglas de derecho en atención al caso particular que tiene ante sí, con prescindencia de otras consideraciones irrelevantes al caso sometido a su cognición y decisión. Este razonamiento además debe verificarse desde la posición de un tercero ajeno a las partes y a los intereses en conflicto, y teleológicamente orientado hacia la tutela de derechos fundamentales. Lo que no es un lugar común, en cambio, a lo menos en el contexto nacional, es el análisis sobre diseños institucionales judiciales, y cómo estos ayudan a promover o inhibir aquello que

18 Ibid., p. 257. 
Becerra - Corte Suprema y recurso extraordinario: algunas consideraciones...

identificamos como tan central a la función jurisdiccional: la independencia del adjudicador.

Por contraste con la posición del juez así entendida, como un ente esencialmente independiente e imparcial -con desinterés objetivo en la causa- la Administración del Estado es esencialmente interesada y parcial, en la medida en que ella avanza y ejecuta determinados objetivos políticos declarados, fijados por sus más altas instancias decisorias (que a su vez son responsables ante el electorado) ${ }^{19}$ y que se estiman deseables puesto que la consecución de dichas finalidades apuntaría, en último término, a un mayor bienestar de la comunidad en su conjunto, cuestión esta última que constituye, en definitiva, la razón de ser del Estado. La actuación de la Administración se justifica en el interés general.

Para reformular esta noción, podemos decir que cuando la Administración participa de conflictos e incide en su decisión, lo hace inevitablemente como parte interesada (en la promoción de aquellos intereses generales o de política pública declarados como deseables y que ella fija, promueve y ejecuta).

El juez, a diferencia del Administrador, es llamado inexcusablemente ${ }^{20}$ a aplicar el derecho a un caso concreto, decidiendo una contienda entre partes por intermedio de esta aplicación. Esta contienda debe ser adjudicada conforme a lo que es justo en el caso concreto; el caso sometido a la decisión del juez no puede ser, en un Estado de Derecho, una ocasión para que el adjudicador avance sus propias metas o lleve a cabo, a través de la contienda entre partes, su particular visión de lo que es "bueno" o lo que cree deseable en materia de políticas públicas. A quien así lo hiciera le reprocharíamos, a lo menos, que es un mal juez, pues, al final del día, repugna a nuestras concepciones más básicas de justicia que alguien pueda ser juez y parte interesada a la vez.

Si el juez se ve sometido o tentado a tomar en consideración elementos ajenos al caso para decidir lo que es "justo" entre las partes de dicho caso, cruza

\footnotetext{
${ }^{19}$ Vid. Montt, Santiago: Autonomia y responsabilidad: dos expresiones de la vocación justificadora del derecho administrativo y sus principios fundamentales" Documento de Trabajo $\mathrm{N}^{\circ} 4$, Centro de Regulación y Competencia, Facultad de Derecho Universidad de Chile, disponible en:

http://www.regcom.uchile.cl/inicio/trabajos/documentos-de-trabajo/documento-de-trabajo-4 [fecha de consulta: 23.09.12].

20 Calamandrei caracterizaba al derecho procesal -a los procedimientos judiciales- como una particular forma de razonamiento formal que, a diferencia de otros tipos de razonamiento, tales como el razonamiento científico, siempre debe arribar a una respuesta, y la decisión es siempre necesaria, puesto que en ello se juega la legitimidad del Estado como garante de la paz social, monopolizando el uso de la fuerza en la resolución de conflictos. Por ello le está vedado al juez -a diferencia del científico- alegar non liquet cuando no le queda claro el asunto o no puede "emitir un diagnóstico" sobre la cuestión planteada. Cfr. Calamandrei, Piero: Proceso y Democracia. Ara Editores, Lima, 2006, pp. 30-31.
} 
una particular frontera donde la posibilidad de una adjudicación en derecho independiente e imparcial se ve gravemente comprometida; y, en los extremos, dicha función será irreconocible, degenerando en un ejercicio de un poder sólo nominalmente jurisdiccional, en el mejor de los casos.

El cruce de esa frontera determina la diferencia entre administrar y juzgar. $\mathrm{Y}$ es precisamente aquí donde entra en juego la relevancia de la configuración institucional seleccionada por el legislador: si dicha configuración institucional no es capaz de anular o al menos limitar severamente el riesgo de que el adjudicador, al atender al caso, utilice dicho caso y a las partes en contienda para avanzar sus propios intereses, los intereses de su gremio, institución o corporación, o para avanzar ciertos intereses colectivos que en su concepto resultan deseables (hacer política pública, diríamos), la decisión independiente e imparcial del caso resulta ilusoria; y la presencia de una verdadera potestad jurisdiccional -en tanto ella es definida por las notas de independencia e imparcialidad- deviene imposible.

Ello explica que la configuración de la función jurisdiccional, y la noción de debido proceso adscrita a la misma, esté determinada por la presencia de ciertas exigencias, condiciones y prohibiciones que propenden a salvaguardar la independencia e imparcialidad del juzgador con prescindencia de consideraciones "eficientistas", y que determinan la naturaleza misma de la potestad jurisdiccional. ${ }^{21}$

Uno de los problemas básicos no sólo del derecho procesal, sino de la política más ampliamente considerada, consiste en que el juez que decide un caso - cualquier caso - teniendo a la vista una finalidad distinta a la de dar a cada uno lo que en derecho corresponde, es un juez que utiliza a las partes como instrumentos para avanzar otros fines: su propia carrera, los intereses de la organización a la cual pertenece, finalidades de política pública o interés general que personalmente o colectivamente el juez o su institucionalidad estima deseables, etcétera. Es decir, deviene en un no-juez, pues la función paradigmática de cada juez -la jurisdicción- es dar a cada uno lo que conforme a derecho le corresponde, dejando fuera toda consideración ajena al caso concreto. Bastante énfasis se ha puesto en la literatura sobre la importancia de la independencia externa del Poder Judicial -sin ella no hay democracia-, pero creemos que la independencia interna es igualmente importante $y$, sin embargo, no ha sido igualmente destacada: sin independencia interna no hay función jurisdiccional.

Esta premisa, la centralidad de la independencia de cada juez para el ejercicio de la jurisdicción, debiera orientar la discusión acerca de cuál debe ser el rol de la Corte Suprema, y cómo, en consecuencia con dicha definición, debe reestructurarse o adecuarse su diseño institucional y funciones. La Corte Suprema,

21 Una útil síntesis de los caracteres sustantivos definitorios de la función jurisdiccional es proporcionada por Bordalí "Principios de una nueva justicia administrativa en Chile", en: Bordalí, A. y Ferrada, J. C.: Estudios de Justicia Administrativa, Santiago, LegalPublishing, Santiago, 2009, pp. 83-85. 
Becerra - Corte Suprema y recurso extraordinario: algunas consideraciones...

si ha de permanecer como un ente jurisdiccional, debiera ser un tribunal de derecho que ejerce jurisdicción, separándose dicha misión de otras tareas como el gobierno judicial, calificación de jueces, funciones legislativas y nombramiento de los miembros del poder judicial. La reunión de todas estas funciones en un sistema judicial verticalizado a cuya cabeza se encuentra la Corte no resulta adecuada para remover o inhibir estímulos de índole egoísta -como promoción del propio interés- en los funcionarios que sirven el cargo de jueces, a la luz de la permanente preocupación que cada funcionario tendrá por su "carrera", las promociones asociadas, remuneraciones, reconocimientos, etcétera. ${ }^{22}$

Un fortalecimiento de la motivación de las decisiones junto con la transparencia en las deliberaciones coadyuva a desterrar el conformismo que acusara Calamandrei y reduce los espacios de discrecionalidad, junto con las posibilidades de que en la decisión interfieran consideraciones de índole extra jurídica. El diseño de la Corte Suprema -y el proceso decisorio que observa- no favorece ni la deliberación ni la transparencia ${ }^{23}$ en sus inferiores ni en su interior, sino que favorece, en cambio, el argumento de autoridad ("la Corte ya ha resuelto que...") y la ausencia de motivaciones jurídicas en la decisión ("vistos, se confirma..."). El argumento de autoridad y la deficiente motivación son consistentes con diseños pre republicanos, de corte monárquico, y no resultan adecuados para potenciar la independencia de cada juez en un estado democrático.

La independencia de cada juez individualmente considerado es aquello que caracteriza a la jurisdicción. ${ }^{24}$ ¿Cómo contribuye el diseño de la Corte al ejercicio de ese poder-deber reglado, en cuya virtud se particulariza la ley al caso concreto y la decisión alcanzada se torna inmutable? Los roles de gobierno judicial y especialmente las facultades disciplinarias, impactan negativamente sobre la probabilidad de un auténtico ejercicio de funciones jurisdiccionales, forzando a jueces inferiores a conformarse a los criterios de los superiores so pena de consecuencias disciplinarias, y permitiendo que la decisión de estos últimos descanse en argumentos de autoridad, castigando a quienes se apartan de tales criterios, ya sea en su calificación, en sus ascensos, o por la vía del recurso de queja.

\footnotetext{
22 En ese sentido, Atria, Fernando: "La Improbabilidad de la jurisdicción" (Expansiva, 2007), http://www.expansiva.cl/publicaciones/en_foco/detalle.tpl?iddocumento=14112007100957, op. cit.; Calamandrei: Proceso y Democracia. op. cit.; también Squella Narducci, Agustín: "Independencia interna del Poder Judicial: Ante quiénes, en qué y para qué tenemos jueces independientes," en $\mathrm{La}$ judicatura como organización, Santiago, Expansiva \& Instituto de Estudios Judiciales, 2007, pp. 9-32.

${ }^{23}$ Recordemos que una cuestión tan central en los tribunales colegiados como es el debate de la decisión es declarado secreto por la ley. Art. 81 COT.

${ }^{24}$ Para nuevas perspectivas sobre el concepto y sentido de la jurisdicción, vid. Guilherme Marinoni, Luiz/Pérez Ragone, Álvaro/Núñez Ojeda, Raúl: Fundamentos del proceso civil. Hacia una teoría de la adjudicación, Abeledo Perrot LegalPublishing, Santiago, 2010.
} 
De este modo, existe una suerte de deuda pendiente del legislador con la función jurisdiccional, pues el mantenimiento en el vértice del Poder Judicial de potestades disciplinarias y de calificación funcionaria al mismo tiempo que la potestad jurisdiccional no resulta funcional a la independencia e imparcialidad que cada juez individualmente considerado debe poseer para resolver un caso sometido a su conocimiento: la independencia del juez es una exigencia ineluctable de un debido proceso, y por ende de un Estado democrático de derecho. Esta es una cuestión de la cual el legislador, en el contexto del proceso de revisión de nuestro sistema de justicia denominado Reforma Procesal Civil, debiera hacerse cargo, con miras a fortalecer el ejercicio de una auténtica potestad jurisdiccional.

De este modo, el NCPC debe ajustarse a las exigencias constitucionales sobre debido proceso. Una de esas exigencias consiste precisamente en el derecho que asiste a los justiciables a ser juzgados por un tribunal independiente e imparcial, como se explicará a continuación, lo que está íntimamente relacionado con otra garantía: el derecho al recurso.

\section{Exigencias constitucionales para la Reforma: cinco tópicos para la discusión}

En vista de las consideraciones antes expuestas, se proponen a continuación cinco tópicos para reflexión en torno al rol de la Corte Suprema en materia de recursos en un estado democrático de derecho, de cara a la discusión sobre las necesarias reformas que nuestro sistema judicial demanda.

\subsection{Diluyendo la función jurisdiccional}

Creemos fundamental evaluar el mérito o demérito de las reformas propuestas en el NCPC a la luz de las garantías constitucionales y los tratados internacionales sobre derechos humanos ratificados por Chile. Consecuentemente, el rol que se asigne a la Corte Suprema en el contexto de la Reforma Procesal Civil debe permanentemente ser evaluado bajo el prisma de qué constituye la mejor y más razonable configuración institucional en función de la tutela de las garantías de las personas, entre ellas el derecho a ser juzgados por un juez independiente e imparcial.

Como dijimos al comienzo de este trabajo, el NCPC propone a debate una posición específica acerca del rol que ha de cumplir la Corte Suprema en materia jurisdiccional de cara a la reforma, innovando sobre el régimen recursivo mediante el establecimiento del denominado recurso extraordinario. ${ }^{25}$

\footnotetext{
${ }^{25}$ NCPC marzo 2012, Libro III, Título V, arts. 405 y ss.
} 
Becerra - Corte Suprema y recurso extraordinario: algunas consideraciones...

Pero ¿qué exigencias constitucionales debiera observar el recurso extraordinario? ¿Cualquier configuración será constitucionalmente admisible?

El proceso es en sí mismo un instrumento de tutela de derechos establecido en función de la protección de la persona humana. Dicha función de tutela no puede sucumbir ante el proceso sin que ello signifique la negación de su cometido y sentido último, en perjuicio de los derechos del individuo. Como destacaba Couture, ${ }^{26}$ en su desenvolvimiento lógico, las premisas de este razonamiento son: a) que la Constitución presupone la existencia de un proceso como garantía de los derechos de la persona, el proceso es instrumento y no fin; b) que la ley, en el desenvolvimiento normativo jerárquico de preceptos, debe instituir ese proceso; c) pero la ley no puede instituir formas que hagan ilusoria la concepción del (debido) proceso plasmada en la Constitución (derecho fundamental de la persona humana); y d) si la ley instituyera una forma de proceso que privara al individuo de una razonable oportunidad para ejercer su derecho, sería inconstitucional.

Este razonamiento desde luego se dirige primariamente al legislador, en cuanto a este compete concretizar las garantías de un debido proceso; pero en cuanto este falle y se aparte de los parámetros, haciendo ilusoria la garantía del debido proceso, el juez (constitucional) debe asumir su rol tutelar a posteriori. Ahí radica la importancia del Tribunal Constitucional, sí, pero antes de llegar a ese extremo, es deseable que el legislador maximice su actividad desde una perspectiva de protección de derechos: la ley debe instituir formas y arreglos institucionales funcionales a la protección de las garantías de las personas, entre ellas, el derecho al recurso y a ser juzgadas por jueces independientes e imparciales. Además, y desde la perspectiva constitucional, se producen conflictos desde que tanto el Tribunal Constitucional como la Corte Suprema serán intérpretes finales de la Constitución, cuestión que se comentará infra, lo que refuerza la necesidad de visibilizar aquello que, por obvio, a veces resulta preterido: que el norte de la (toda) reforma deben ser los derechos fundamentales de la persona.

Sobre el derecho al recurso, el Tribunal Constitucional ha fallado que el debido proceso comprende el derecho a interponer recursos para ante tribunales superiores de modo tal que la sentencia dictada pueda ser revisada:

DECIMOCUARTO: Que el constituyente, como se expresó, se abstuvo de enunciar las garantías del procedimiento racional y justo, ordenando al legislador precisarlas en cada caso.

La Comisión de Estudio de la Nueva Constitución (sesiones 101 y 103) discutió extensamente esta materia, prefiriendo no enumerar los

\footnotetext{
${ }^{26}$ Couture, Eduardo J.: Fundamentos del derecho procesal civil, reimp., Obras, Puntolex Thomson Reuters, Argentina, 2010, p. 133.
} 
REJ - Revista de Estudios de la Justicia - No 17 - Año 2012

requisitos del debido proceso, sino atribuir a la ley el deber de establecer las garantías de un racional y justo procedimiento, dejándose constancia que tales atributos se concretan, entre otros elementos, en principios como el de la igualdad de las partes y el emplazamiento, materializados en el conocimiento oportuno de la acción, la posibilidad de una adecuada defensa y la aportación de la prueba, cuando ella procede.

En el mismo sentido se ha pronunciado este Tribunal Constitucional (sentencias Roles números 376, 389, 481, entre otras) y la Corte Suprema, estableciendo ésta (C.S., 5 diciembre 2001, R.G.J., 258 ) que "conforme a la doctrina nacional, el derecho a un proceso previo, legalmente tramitado, racional y justo, que la Constitución asegura a todas las personas, debe contemplar las siguientes garantías: la publicidad de los actos jurisdiccionales, el derecho a la acción, el oportuno conocimiento de ella por la parte contraria, el emplazamiento, adecuada asesoría y defensa con abogados, la producción libre de pruebas conforme a la ley, el examen y objeción de la evidencia rendida, la bilateralidad de la audiencia, la facultad de interponer recursos para revisar las sentencias dictadas por tribunales inferiores... ${ }^{27}$

Si bien breve, el párrafo anteriormente citado pone de manifiesto, al menos, el reconocimiento jurisprudencial de que el debido proceso efectivamente exige la posibilidad de solicitar la revisión de la decisión por instancias superiores.

Con mayor profundidad, y armada de una dogmática constitucional superior, la Corte Interamericana de Derechos Humanos ha establecido que el derecho al recurso integra la garantía de un debido proceso. Así, condenó al Estado de Costa Rica en un conocido fallo, basado en que su sistema penal solamente confería un recurso de casación que no permitía la revisión de los hechos del pleito. ${ }^{28}$ Resulta notable consultar en este fallo la opinión plasmada en el voto concurrente del Juez Sergio García Ramírez, quien expresa, en primer término, que el derecho al recurso "concurre a integrar el debido proceso legal, extendido por la Corte a todos los supuestos de enjuiciamiento, no sólo a los de carácter penal...".

Sostiene además que:

\footnotetext{
${ }^{27}$ Rol 478-2006. El destacado es nuestro.

28 Se trata de la conocida sentencia dictada en el caso "Herrera Ulloa con Costa Rica" del año 2004, en el que la Corte resolvió que “...en el presente caso, los recursos de casación presentados contra la sentencia condenatoria de 12 de noviembre de 1999 no satisficieron el requisito de ser un recurso amplio de manera tal que permitiera que el tribunal superior realizara un análisis o examen comprensivo e integral de todas las cuestiones debatidas y analizadas en el tribunal inferior...”. El texto de la sentencia puede ser consultado en: http://www.corteidh.or.cr/docs/casos/articulos/seriec 107 esp.pdf [fecha de consulta: 05.12.11].
} 
Becerra - Corte Suprema y recurso extraordinario: algunas consideraciones...

[el recurso exigido en la Convención trata] no sólo de cuidar, en determinados extremos, la pulcritud del proceso o de la sentencia. Por lo tanto, ese recurso ante juez o tribunal superior -que sería superior en grado, dentro del orden competencial de los tribunales- debe ser uno que efectivamente permita al superior entrar en el fondo de la controversia, examinar los hechos aducidos, las defensas propuestas, las pruebas recibidas, la valoración de éstas, las normas invocadas y la aplicación de ellas...

...En el presente caso se hizo uso del recurso de casación, único que contiene el sistema procesal del Estado, por cuanto fue suprimido el recurso de apelación, con el que se integra la segunda instancia. De ninguna manera pretende la Corte desconocer el papel que ha cumplido, en una extensa tradición procesal, y la eficacia que ha tenido y tiene el recurso de casación -no obstante tratarse, generalmente, de un medio impugnativo excesivamente complejo y no siempre accesible a la generalidad de los justiciables-, si no ha tomado en cuenta el ámbito de las cuestiones que, conforme al Derecho positivo, se hallan abarcadas por un régimen concreto de casación y están sujetas, por lo mismo, a la competencia material del tribunal superior. En la especie, la casación no posee el alcance que be descrito supra, sub 30, y al que se refirió la Sentencia de la Corte Interamericana para establecer el alcance del articulo 8.2 b) del Pacto de San José. Es posible que en otras construcciones nacionales el recurso de casación -que también presenta diferentes desarrollosabarque puntos que regularmente corresponden a una apelación, además de la revisión de legalidad inherente a aquél...

Citando luego otro fallo de trascendencia, el Juez García Ramírez añade que:

Con respecto a la sentencia dictada en el Caso Castillo Petruzzi, un Juez de la Corte produjo un Voto concurrente razonado en el que se refirió a este asunto, inter alia, aunque lo hiciera a propósito de la inobservancia del recurso en la hipótesis de un juicio militar: "no se respetó el derecho... a una segunda instancia (porque los organismos que intervinieron en la revisión de la sentencia) no se desempeñaron como tribunales que reexaminaran la totalidad de los hechos de la causa, ponderaran el valor del acervo probatorio recaudaran las pruebas adicionales que fueran menester, produjeran, de nuevo, una calificación jurídica de los hechos... etc. (Voto concurrente del Juez Carlos Vicente de Roux Rengifo, correspondientes a la Sentencia del Caso Castillo Petruzzi y otros, del 30 de mayo de 1999)...

En este punto, debemos recordar que la Convención Americana de Derechos Humanos reconoce el derecho al recurso en su artículo $8^{\circ} \mathrm{N}^{\circ} 2$ letra h):" $N^{o} 2$. Toda persona inculpada de delito tiene derecho a que se presuma su inocencia mientras no se 
REJ - Revista de Estudios de la Justicia - No 17 - Año 2012

establezca legalmente su culpabilidad. Durante el proceso, toda persona tiene derecho, en plena igualdad, a las siguientes garantías minimas: b) derecho de recurrir del fallo ante el juez, o tribunal superior". En el mismo sentido apunta el Pacto Internacional de Derechos Civiles y Políticos en su artículo 14.

Aparece de manifiesto entonces que el rol de los tribunales superiores de justicia es uno de tutela de derechos fundamentales, y que esa actividad de tutela -vía recursos- debiera ser lo suficientemente amplia como para abordar tanto las cuestiones de hecho como de derecho involucradas en el caso. El rol de tutela de derechos fundamentales no puede circunscribirse, desde luego, a una sola garantía constitucional, desde que todas ellas -las reconocidas por la Constitución y tratados internacionales- integran ese catálogo de derechos e inmunidades que el Estado se ve obligado a respetar y promover, y para cuya precisa protección se establece la institucionalidad judicial.

Una primera objeción en este sentido puede ser formulada en general al recurso extraordinario, como mecanismo de impugnación a través del cual se provoca la actividad jurisdiccional de la Corte Suprema en el proyecto de NCPC: aquél está concernido fundamentalmente con el resguardo de la garantía de igualdad ante la ley a través de una función uniformadora de jurisprudencia, más no con otras garantías constitucionales.

El recurso extraordinario procedería en contra de sentencias definitivas e interlocutorias inapelables, que pongan término al juicio o hagan imposible su continuación, dictadas por Cortes de Apelaciones; ${ }^{29}$ cuando en la sentencia se haya agraviado a la parte afectando un interés general. Es decir, se exige un agravio calificadísimo: el agravio, condición de la impugnación, debe comportar al mismo tiempo la afectación de un "interés general".

¿Y cuándo se afecta el interés general? Es también calificado por el legislador, restringiéndose a la hipótesis del artículo 409: infracción esencial de una garantía fundamental $y$ en caso que considere pertinente fijar, uniformar, aclarar o modificar una doctrina jurisprudencial. Nótese la $y$ en cursivas: pese a que el enunciado de la norma habla de "los siguientes casos", al parecer termina estructurando la condiciones a) y b) como condiciones copulativas, tal y como observó un equipo académico de la facultad de derecho de la Universidad de Chile: "la utilización de la conjunción conjuntiva "y", y no de la conjunción disyuntiva "o", al final de la letra a) del inciso 20 del artículo 409, da cuenta de que se deben reunir ambas causales para que exista "interés general" (a pesar de que, contradictoriamente, el inciso se refiere más arriba a

\footnotetext{
${ }^{29}$ Art. 406 NCPC. Nótese cómo la redacción parece excluir a la jurisdicción arbitral del alcance de la Corte.
} 
Becerra - Corte Suprema y recurso extraordinario: algunas consideraciones...

"los siguientes casos" en que se encontraria comprometido el "interés general"), cuestión que vuelve aún más excepcional el recurso". 30

Más allá de la redacción específica de la norma, lo que cabe destacar en esta ocasión es que el proyecto obliga a la Corte a razonar sobre derechos fundamentales, pero en la perspectiva de lograr uniformidad jurisprudencial o, en palabras del Mensaje con que se despachó el proyecto en lo atinente al rol de la Corte, para "dar coherencia y unidad a los criterios de decisión de los tribunales del país". No es la garantía fundamental per se lo que gatilla la actividad de la Corte; es la búsqueda de unidad en los criterios de decisión a propósito de garantías fundamentales, calificado el interés general involucrado en los términos antedichos por el legislador.

Todo ello hace tremendamente excepcional la procedencia del recurso extraordinario, y ése es precisamente el objetivo perseguido: que la Corte conozca de pocos casos, para que pueda desarrollar una jurisprudencia cualitativamente superior a la que puede generar con su carga actual de trabajo, y de esa manera poder cumplir adecuadamente el rol de uniformadora de jurisprudencia que el NCPC le asigna.

El problema puede advertirse entonces, entre lo que constituye o debe constituir actividad jurisdiccional propiamente tal, y otro tipo de funciones públicas: si la jurisdicción consiste en ese poder-deber reglado, en cuya virtud se particulariza la ley al caso concreto excluyendo toda consideración ajena a lo que en derecho corresponde a las partes en conflicto, ¿la Corte Suprema ejerce "jurisdicción” así entendida cuando conoce de un recurso extraordinario, en los términos propuestos en el NCPC? ¿Resulta adecuada la sola consideración por la garantía de la igualdad ante la ley, con prescindencia de otras garantías fundamentales potencialmente en juego?

Cuando se encomienda a la Corte velar por la consistencia o uniformidad en la jurisprudencia al afectarse un "interés general" calificado por el legislador, la Corte ya no está mirando a las partes en disputa, sino que está considerando el contexto político-jurídico más amplio; es decir, ya no está operando como adjudicadora de lo que en derecho corresponde a las partes que acuden a ella, sino que está velando por sentar criterios generales para que los tribunales del sistema -y también la sociedad en general- cuenten con criterios de previsibilidad acerca de cómo deben ajustar sus fallos (los tribunales) o su conducta (la sociedad) hacia el futuro. Esto es más cercano a una función de política pública que a la función jurisdiccional, en la medida en que se encomienda a la Corte promover lo que estime el criterio correcto respecto de un problema jurídico, en nombre del interés general y con una finalidad esencialmente prospectiva.

${ }^{30}$ Informe del departamento de derecho privado de la Facultad de Derecho de la Universidad de Chile, titulado "Comentarios al Proyecto de Nuevo Código Procesal Civil", p. 7, no publicado. 
Consecuentemente, la específica configuración escogida para ese particular mecanismo de impugnación que se denominó recurso extraordinario en el NCPC apuesta por privar a la Corte de una función auténtica y decididamente jurisdiccional, para en cambio asignarle el rol de fijar criterios uniformes con finalidades prospectivas en nombre de un interés general calificado. Dicho de otro modo, la Corte Suprema ya no hará justicia, dando a cada uno lo suyo, sino usando la resolución del caso concreto para conseguir una finalidad ajena al caso: la uniformidad sistémica en torno a doctrinas y criterios divergentes, lo que milita en una función de carácter legislativo antes que jurisdiccional.

Y en efecto, fijar criterios generales hacia el futuro acerca a la Corte Suprema hacia funciones marcadamente legislativas antes que jurisdiccionales. En esa perspectiva, el establecimiento de un mecanismo discrecional de selección de casos resulta consistente con la configuración escogida, dado que en la perspectiva de ejercer funciones cuasi-legislativas, sentando criterios generales para el futuro, resulta necesario poder escoger casos que presenten un alto contenido "público" para generar una labor útil.

Pero ello deviene en una Corte irrelevante, cuya función jurisdiccional se diluye, puesto que si de sentar criterios prospectivos en torno a finalidades de interés general se trata, el Legislador y la Administración se encuentran en una mejor posición institucional comparativa y dotados de mecanismos técnicos apropiados para lograrlo. En efecto, la Administración cuenta con una pluralidad de servicios especializados en una diversidad de temas que le permiten abordar la regulación sectorial de mejor modo; y el Legislador cuenta con el debate público para -idealmente- crear las mejores decisiones acerca de cómo hemos de comportarnos en nuestras tratativas con los demás hacia el futuro. Administración y Legislación cuentan con mayor legitimidad democrática para implementar soluciones acerca de tópicos controversiales y para mediar entre intereses divergentes en una forma tal, que aunque no exenta de problemas, pueda ser reputada como una solución razonable entre varias posibles. Por lo anterior, parece dudosa la opción por un tribunal unificador de jurisprudencia en un país de tradición de derecho común: el rol generador y unificador de criterios de decisión resulta consistente con la creación jurisprudencial de derecho mediante precedente vinculante; pero con un sistema cuyo derecho es de creación legislativa, genera más incertidumbres que las certezas pretendidas.

Graficando el punto con instituciones foráneas, la Corte Suprema norteamericana tiene una función y una tradición paradigmáticamente política y ella crea normas generales y obligatorias hacia el futuro porque la sociedad en que se inserta la ha dotado de esa específica función y de herramientas y formas de conocimiento idóneas a ese fin. La Corte Suprema se comprende a sí misma como un órgano político, cuyas decisiones dependen más de la experiencia que del silogismo: 
Becerra - Corte Suprema y recurso extraordinario: algunas consideraciones...

"The felt necessities of the time, the prevalent moral and political theories, intuitions of public policy, avowedor unconscious, even the prejudices which judges share with their fellow-men, have had a good deal more to do than the syllogism in determining the rules by which men should be governed". ${ }^{31}$

Pero incluso teniendo esa función, la Corte norteamericana se autolimita ("judicial self-restraint') tratándose de problemas controversiales, pues como reconoce que carece de legitimidad democrática, entiende que ese tipo de decisiones debieran ser adoptadas por el Parlamento, dotado de la legitimidad necesaria para ello. Los jueces no son expertos en la compleja regulación sectorial, y no forman parte de ninguna de las ramas políticas del Estado. Los tribunales deben, en algunos casos, conciliar intereses políticos en conflicto, pero no sobre la base de las preferencias políticas personales del propio juez. En cambio, una agencia estatal a la cual el Congreso ha delegado responsabilidades de ejecución de políticas puede, dentro de los límites de dicha delegación, basarse en los puntos de vista del propio órgano administrativo involucrado sobre lo que constituye la política correcta, para informar sus decisiones. Mientras que las agencias no son directamente responsables ante las personas, el Ejecutivo lo es, y por ello resulta enteramente apropiado para esta rama del Estado adoptar dichas decisiones de política, resolviendo los intereses en disputa que el Congreso mismo inadvertidamente dejó sin resolver, o intencionalmente dejó para ser resueltos por la agencia encargada de la administración de la norma a la luz de la realidad cotidiana.

La cuestión impone, en último término, volver sobre nuestra concepción de la teoría de separación de poderes y cómo ésta proscribiría (o no) que la Corte asume funciones cuasi-legislativas. Esta lectura de la separación de poderes es algo diferente a la que predomina en algunos países pertenecientes a la tradición del common law, donde el principio de separación de poderes protege de la concentración de funciones, pero no exige (o se ha entendido que no exige) en sí misma, la compartimentalización de tales funciones. Así, en el Reino Unido, las funciones ejecutivas y legislativas están relativamente integradas; y en los EE.UU., no obstante tener una separación de poderes más marcada, la Corte Suprema nunca ha interpretado su Constitución como prohibiendo la delegación de funciones legislativas o judiciales en entes administrativos. ${ }^{32}$ En el sistema anglosajón, como nos recuerda Nieva, los tribunales superiores deben marcar no sólo la pauta, sino que la norma jurídica obligatoria a seguir; ${ }^{33}$ en tal contexto, un tribunal unificador de jurisprudencia resulta consistente, pero en un sistema que parte

\footnotetext{
${ }^{31}$ El juez O.W. Holmes, citado por: Posner, Richard A.: "The meaning of judicial self-restraint," Indiana Law Journal 59, 1983, p. 2,

http://www.repository.law.indiana.edu/cgi/viewcontent.cgi?article $=2187 \&$ context $=\mathrm{ilj} \quad[$ fecha de consulta: 4.10.12].

32 Cfr. Cane, Peter: Administrative tribunals and adjudication. Hart Publishing, reimp., Oxford, 2010, p. 70.

${ }^{3}$ Nieva Fenoll, Jordi: El recurso de casación, Abeledo Perrot, Legal Publishing, 1ª ed., Santiago, 2010, p. 27.
} 
constitucionalmente de la existencia de una más o menos marcada separación de funciones legislativas y adjudicativas, un tribunal unificador, a medio camino entre ambas funciones, pudiendo interferir ambas, bien podría requerir de una reforma a la Constitución, y entraría en permanente tensión con las demás ramas.

La judicatura, en definitiva, carece de esa legitimidad democrática y preparación para imponer criterios generales a la sociedad en temas controversiales, y nuestro sistema constitucional no está diseñado para que lo hagan, por lo cual creemos que no resulta aconsejable que ella aborde esa tarea; no al menos sin que exista una redefinición explícita e integral acerca de cuál es el rol de la Corte Suprema en el ordenamiento nacional, que podría requerir una reforma constitucional; definición que hasta el día de hoy no ha sido abordada, ni en el ordenamiento vigente ni en el proyecto de NCPC.

\section{2 ¿Ius constitutionis vs. ius litigatoris? El falso dilema}

Si, como hemos dicho, el proceso es en sí mismo un instrumento de tutela de derechos establecido en función de la protección de la persona humana, y es en ella que el Estado debe centrar su acción, la disyuntiva entre optar por el ius constitutionis y el ius litigatoris no es más que un mal planteamiento del debate: no puede realizarse el primero sin el segundo.

De conformidad con la jurisprudencia previa del Tribunal Constitucional, los tratados internacionales sobre derechos humanos se encuentran sujetos a la Constitución Política, ${ }^{34}$ derivando su legitimidad de la propia Constitución, careciendo de preeminencia sobre la misma. En efecto, la sentencia del Tribunal Constitucional sobre el Estatuto de Roma vino de alguna forma a cristalizar la posición jurisprudencial sobre la relación entre Tratados Internacionales y la Constitución, inclinando la balanza hacia la primacía de esta última frente a la problemática pregunta que impone el art. $5^{\circ}$ inciso segundo de la Constitución y su mandato de limitación de soberanía por los derechos fundamentales, y protección y promoción de tales derechos: todo tratado internacional se encuentra jerárquicamente subordinado a la Constitución. Para que tuvieran una jerarquía superior, la Constitución tendría que haberlo declarado expresamente, sugirió el Tribunal Constitucional en dicha sentencia:

Que, en este aspecto, es relevante recordar que aunque aparezca obvio, la norma constitucional reformada no consagró que los tratados internacionales sobre derechos esenciales tuvieran una jerarquía igual o superior a la Ley Fundamental. ${ }^{35}$

\footnotetext{
34 Tribunal Constitucional, sentencia “Corte Penal Internacional”, Rol No 346 (2002).

35 Considerando 62 rol 346.
} 
Becerra - Corte Suprema y recurso extraordinario: algunas consideraciones...

Esta posición es discutible ${ }^{36-37}$ pero dicha discusión excede del objeto de este trabajo. La cuestión relevante aquí consiste en constatar que en su rol de uniformación de jurisprudencia en el recurso extraordinario la Corte es llamada a razonar sobre garantías fundamentales, pero éstas son normas políticas de carácter abierto, mientras que el razonamiento de los jueces de instancia, aunque informado por los principios constitucionales, gira en torno a la legislación que particulariza esas normas constitucionales, dotándolas de contenido específico.

¿Cómo juega entonces la relación entre las Cortes de Apelaciones, cuyo análisis gira en torno a la legislación -informada por las normas Constitucionalesaplicable al caso concreto, y la Corte Suprema, siendo que esta última es llamada a razonar en torno a la Constitución y el interés general? Algunos han planteado el punto como una disyuntiva: ¿debe ocuparse la Corte de resolver en justicia el caso concreto, o velar por criterios adecuados de interés general?

El dilema ha sido falsamente propuesto como una disyuntiva entre dos opciones, a nuestro juicio.

En efecto, se ha dicho que "es necesario tomar partido en cuanto a otorgar preeminencia a la tutela del ius litigatoris, es decir, optar por la búsqueda de la solución interpretativa que permita pronunciar una resolución que mejor se adapte a las peculiaridades del caso concreto, o al ius constitutionis, es decir, optar por la solución más justa sobre la base de criterios generales de interpretación más que la solución de un caso particular. La opción entre ambas posturas no es menor, dado que la primera se centra en la solución del conflicto según criterios de justicia, y la segunda en la creación de una norma para uniformar la jurisprudencia, más que en la solución de un asunto particular". ${ }^{38}$

Creemos que el dilema es un falso dilema porque fuerza el debate sobre la base de una petición de principio: asume que existen dos opciones antagónicas, y que debemos escoger una.

Se pierde de vista de ese modo que el ius constitutionis y el ius litigatoris son, al final, una única y misma cuestión: el derecho de la constitución -las garantías fundamentales- es el derecho de la persona; el interés público, el Estado mismo, no se justifican, sino en cuanto tienen en su centro y eje de acción a la persona

\footnotetext{
36 Sobre la idea de una identidad jerárquica entre Constitución y Tratados, cfr. Nogueira Alcalá: Humberto, "Los tratados internacional en el ordenamiento jurídico chileno", Ius et Praxis $\mathrm{N}^{\circ} 2$, año 2 (1997), disponible en: http://redalyc.uaemex.mx/src/inicio/ArtPdfRed.jsp?iCve=19720203.

${ }^{37}$ Ello, sobre todo considerando el texto actual del art. $51 \mathrm{CPR}, \mathrm{N}^{\circ} 1$ inciso $5^{\circ}$.

38 Maturana Miquel,Cristián: “¿Presencia del recurso de casación en Chile durante el Siglo XXI?”, Revista de Estudios de la Justicia 12, 2010, p. 328, disponible en: http://www.revistas.uchile.cl/index.php/RECEJ/article/viewFile/15240/15653 [fecha de consulta: 27/09/12].
} 
humana. Luego, no existe interés público que pueda ser realizado sin la persona, a espaldas de la persona o -lo que quizás resulta más grave- a costa de la persona. La única justificación de la institucionalidad judicial es la persona y la protección de sus garantías fundamentales: el estado está al servicio de la persona humana, ${ }^{39} \mathrm{y}$ no al revés. Luego, no es constitucionalmente admisible velar por el ius constitutionis sino velando, al mismo tiempo, por el ius litigatoris, siendo el primero un medio para la realización efectiva de este último.

Creemos que no resulta necesario sacrificar la justicia para los litigantes del caso concreto en aras del interés general: el desafío radica en buscar configuraciones institucionales que maximicen ambas. En nuestro ordenamiento actual, la función que cumple el recurso de casación se manifiesta en la defensa del derecho del justiciable (ius litigatoris) y, a su vez, en la defensa del propio ordenamiento jurídico (ius constitutionis): ${ }^{40}$ la corte de casación vela por la recta aplicación de la ley con el fin de velar mejor por la defensa del ciudadano. Luego, si el recurso de casación ha probado ser insatisfactorio dada la práctica generada a su respecto por la Corte Suprema, es necesario explorar configuraciones que inhiban estos defectos, pero sin perder de vista la finalidad última de defensa del ciudadano: la persona, el recurrente, no puede ser preterida. Y es que el papel del ciudadano resulta esencial para el diseño institucional. El profesor Nieva ha planteado esta idea muchísimo mejor que nosotros: "los tribunales de casación deben hacerse del derecho del recurrente, porque si no se ocuparan de ese derecho no podrían cumplir la función nomofiláctica. O dicho de otro modo, cuanto menos se ocupen de esas supuestas "pequeñeces" de los recurrentes, en menor medida podrán cumplir con el ius constitutionis [...] ¿Para qué queremos un tribunal de casación, concebido para proteger el ordenamiento jurídico, que en realidad no protege aquellas partes de dicho ordenamiento que son más próximas al ciudadano?". ${ }^{41}$

Con la configuración actual del proyectado recurso extraordinario, se opta por confiar a la Corte no con el rol de impartir justicia material a las partes que han acudido a ella, sino en crear "normas" (vacilamos al usar este término, en propiedad) o pautas de carácter general y abstracto a propósito de un caso concreto, calificado como de interés general. Por tanto, el proyecto sacrifica el ius litigatoris en pos de otorgar a la Corte una indefinida y ambigua finalidad de índole cuasi-legislativa -general y prospectiva- sin que se hayan explicitado adecuadamente los fundamentos de por qué apartarse tan radicalmente de aquello que la Constitución prescribe: que el centro de la acción estatal debe estar en la persona.

\footnotetext{
${ }^{39}$ Art. $1^{\circ} \mathrm{CPR}$.

40 Delgado Castro, Jordi: "El certiorari: Un agente extraño en manos de nuestra Corte Suprema", Actualidad Jurídica 22, Julio 2010, p. 367.

${ }^{41}$ Nieva Fenoll: El recurso de casación, op. cit. p. 47.
} 
Becerra - Corte Suprema y recurso extraordinario: algunas consideraciones...

\subsection{Corte Suprema vs. Tribunal Constitucional: tensión institucional}

La protección del ius constitutionis no puede concebirse sin el ius litigatoris. El problema gira indefectiblemente sobre los derechos fundamentales. Y si ello es así, la existencia de dos "intérpretes últimos" de la Constitución, del ius constitutionis y el ius litigatoris, con toda probabilidad será fuente de conflicto, en perjuicio de la persona. Como mencionamos con anterioridad, a través del recurso extraordinario se impone a la Corte la misión de razonar en una perspectiva de interés general sobre la base de derechos fundamentales, normas esencialmente abiertas y que admiten una pluralidad de respuestas constitucionalmente plausibles para un mismo problema, mientras que el tribunal de instancia, sin desatender la Constitución, está centrado en el caso concreto aplicando la legislación vigente. Tenemos así que existen dos instituciones cuya misión central será hablar sobre el derecho de la Constitución, proveyendo de decisiones en base a ella y razonando sobre derechos fundamentales: la Corte Suprema y el Tribunal Constitucional. El problema queda de inmediato en evidencia: existe un problema de superposición de competencias constitucionales que ha existido y que existe hasta hoy en día entre las máximas Cortes de nuestra nación -la Corte Suprema y el Tribunal Constitucional- con la consiguiente tensión político-institucional que dicha superposición genera.

La Corte Suprema deberá decidir sobre un caso sometido a su cognición cuando éste envuelva un interés general calificado por la afectación de garantías fundamentales. El Tribunal Constitucional, a su turno, interactúa con los litigantes del caso sometido al conocimiento de tribunales ordinarios fundamentalmente a través de dos mecanismos: uno, la solicitud de inaplicabilidad de un precepto legal en un caso concreto por provocar efectos contrarios a la Constitución; el otro, la solicitud de declaración de inconstitucionalidad para purgar del ordenamiento una norma por haber sido declarada previamente inconstitucional.

Se advierte de inmediato que nuestra institucionalidad estará comprendida por dos órganos que se pronuncian sobre la afectación de derechos fundamentales, interpretando y fijando el núcleo de las garantías fundamentales: uno para obtener la revisión de un caso, el otro para declarar inaplicable un precepto legal que tiene influencia decisiva sobre un caso. No obstante ello, parece no haberse articulado cómo precisamente deberán interactuar ambos. Como advierte una autora,

Especialmente grave puede llegar a ser la disparidad jurisprudencial en materia de derechos fundamentales, pues así como los ciudadanos en tanto destinatarios de las normas no estarán en condiciones de conocer el concreto ámbito de protección de sus derechos y aplicación de las normas, así tampoco los poderes públicos sabrán cuál es la extensión de su esfera de acción. En Chile el asunto es especialmente preocupante, si consideramos que no existe ninguna disposición que establezca la fuerza vinculante de las decisiones de la judicatura ordinaria ni de la constitucional en términos generales, sino por el 
contrario, el artículo 3 de nuestro Código Civil consagra el efecto relativo de las sentencias, con lo cual se acentúa la dispersión de nuestra jurisprudencia y la incerteza jurídica de los justiciables. ${ }^{42}$

Los ámbitos de posibles tensiones institucionales son múltiples: a ambos órganos se les impone razonar y generar jurisprudencia sobre derechos fundamentales; ambos tienen una suerte de rol de intérprete último de la Constitución, uno dentro del Poder Judicial, y el otro fuera del Poder Judicial; el Tribunal Constitucional puede decidir sobre la inaplicación de un precepto legal argumentando que su aplicación al caso concreto generaría efectos inconstitucionales, y, no obstante ello, la Corte arribar al mismo resultado por la vía de una interpretación o razonamiento alternativo; etcétera. ¿La jurisprudencia de la Corte Suprema será obligatoria para el Tribunal Constitucional, o se espera a lo menos que se haga cargo de la misma? ¿La Corte deberá atender a la jurisprudencia del Tribunal Constitucional, confluyendo ambas entidades en la misión de razonar sobre la base de garantías constitucionales? La posibilidad de divergencia interpretativa tratándose de derechos fundamentales resulta de la mayor gravedad, y se ve acentuada por la vocación de generalidad que se pretende para el recurso extraordinario, por contraste con la eficacia circunscrita al caso específico de las soluciones del Tribunal Constitucional (salvo la declaración de inconstitucionalidad, claro está).

Las sentencias de inaplicabilidad del Tribunal Constitucional obligan a la jurisdicción ordinaria, pero sólo para el caso concreto en que se dicten. Nada obsta a que se mantengan divergencias interpretativas, con el negativo impacto que ello significa para los justiciables; o incluso, que la Corte no se siente obligada por la interpretación del Tribunal Constitucional. Recordemos que la Corte retiene el conocimiento no sólo del proyectado recurso extraordinario, sino también sobre la acción de protección y la de amparo, como tribunal de segunda instancia, por lo cual retiene una importante labor interpretativa de la Constitución.

Considerando lo anterior, resulta errado afirmar, sin más, que la jurisdicción constitucional corresponde privativamente al Tribunal Constitucional: éste retiene la competencia sobre la inaplicabilidad por inconstitucionalidad, sí, pero la Corte debe interpretar y decidir sobre garantías fundamentales tratándose de acciones de protección, amparo, recursos de nulidad y unificación de jurisprudencia, y, en el futuro, del recurso extraordinario; razón por la cual resulta imperativo armonizar y regular adecuadamente los roles de la Corte Suprema y el Tribunal Constitucional con respecto a la Constitución, de modo tal de maximizar sus posiciones como garantes de derechos fundamentales, sentar claramente cómo han de relacionarse en el ejercicio de sus respectivas funciones y reducir razonablemente la posibilidad de conflictos institucionales. Es posible, incluso, que las Cortes admitan recursos

\footnotetext{
42 Salinas Quero, Celeste: "Nueva justicia constitucional: diálogo de competencias entre la Corte Suprema y el Tribunal Constitucional a la luz del recurso extraordinario del proyecto de ley para un nuevo código procesal civil’, Tesis, Facultad de Derecho, Universidad de Chile, 2010, p. 2.
} 
Becerra - Corte Suprema y recurso extraordinario: algunas consideraciones...

de protección en contra de actos u omisiones del Tribunal Constitucional (en el pasado se han admitido recursos de protección contra resoluciones judiciales). El tema debe ser abordado y zanjado expresamente: los costos de los conflictos institucionales para los justiciables y la sociedad, y para la imagen y confianza en el sistema judicial, son altísimos.

\subsection{Recurso extraordinario: uniformación por intimidación y la necesidad de repensar la carrera judicial}

Como hemos recalcado ya, el NCPC en actual tramitación en el Congreso incluye una singular innovación en el ámbito recursivo. Se trata del recurso extraordinario, cuya finalidad es, según hemos dicho, unificar la jurisprudencia en materia civil. Pero ¿cómo es que se persigue la labor unificadora a través del recurso extraordinario? El único mecanismo de unificación jurisprudencial contemplado por la propuesta de regulación se contiene en el artículo 415 del NCPC:

Art. 415.- Publicación de las sentencias. Todas las sentencias que fallen un recurso extraordinario deberán ser publicadas en la página web del Poder Judicial, conteniendo especialmente un extracto de la doctrina jurisprudencial que se haya establecido con motivo del fallo.

La publicación deberá además señalar nominativamente qué ministros fueron los redactores de los votos de mayoría, de minoría y quiénes concurrieron a la vista y acuerdo.

Sea como Tribunal de Casación o como tribunal que conocerá de este recurso extraordinario, una de las funciones paradigmáticas que se han asignado a la Corte Suprema por más de un siglo es la de garantizar la certidumbre jurídica, ante el evento siempre posible de múltiples y hasta contradictorias interpretaciones judiciales en la labor interpretativa de los órganos que integran el sistema judicial, a lo menos como tribunales ordinarios. Que como tribunal de casación haya cumplido insatisfactoriamente dicha función no es ningún secreto, haciéndonos partes de las críticas del profesor Tavolari en orden a que sigue campeando en la Corte un formalismo hermenéutico casacional inimaginable que no vacila en reproducir los excesos de hace 40 años, con gravísimas secuelas. ${ }^{43}$ Pero, por sobre todo, no logra cumplir en forma satisfactoria con las finalidades que la dogmática le asigna, pues no se percibe una unificación eficaz de la jurisprudencia. Varias razones confluyen en ello.

Primero, sabido es que las sentencias no producen efecto sino para el caso concreto en que se dicten, según dispone el art. $3^{\circ}$ inciso $2^{\circ}$ del Código Civil, con lo cual lo decidido por la Corte Suprema en un caso concreto no tiene la virtud de

\footnotetext{
43 Tavolari Oliveros, Raúl: "Bases y criterios para el nuevo proceso civil chileno", en Proceso civil. Hacia una nueva justicia civil, Editorial Jurídica de Chile, Santiago, 2007, p. 50.
} 
afectar la decisión para otro caso, como regla general. En segundo término, la Corte Suprema ha interpretado en exceso las reglas sobre admisibilidad del recurso, bajo una críptica fórmula sin asidero legal alguno -que la casación es de "derecho estricto" - rigidizando un recurso ya sujeto a bastantes constricciones legales. Ello ha causado que un número importante de recursos sean inadmitidos so pretexto de vicios formales, en lo que constituye las más de las veces una renuncia a ejercer su función con el fin de aligerar una abultada carga de trabajo; generando como consecuencia un detrimento en la función unificadora. Y tercero, es dable aventurar que la Corte no genera una jurisprudencia cualitativamente superior, toda vez que la importante carga de trabajo jurisdiccional y "extrajurisdiccional" (i.e. funciones de gobierno, disciplina, administración presupuestaria, etc.) que se le asigna atentan contra dicha posibilidad.

Ello ha redundado en que, en un sistema que depende de la auctoritas más que de la potestas de la Corte para generar criterios jurisprudenciales, dicha función sea cumplida en forma insatisfactoria.

Ahora, en cuanto al recurso extraordinario, el sistema del NCPC sigue dependiendo de la auctoritas de la Corte, toda vez que no se establece verdaderamente un sistema de jurisprudencia vinculante de la Corte, sino un deber de publicidad de sus fallos, de modo tal que éstos sean más "visibles" tanto para los adjudicadores como para la comunidad jurídica más ampliamente considerada. ¿Pero qué obliga a los tribunales a aplicar los criterios que la Corte desarrolle a propósito de recurso extraordinario? Nada los obliga, a lo menos dentro del sistema del NCPC. Tenemos entonces que la publicidad de las decisiones emitidas en recursos extraordinarios no es cualitativamente diferente a la publicidad de las decisiones emitidas actualmente en casación en el sistema ya vigente en el actual Código de Procedimiento Civil, dado que todas las sentencias de la Corte se publican en el sitio web del Poder Judicial, tal y como proyecta el art. 415 NCPC para las sentencias de recurso extraordinario; son recopiladas y sistematizadas por diversos servicios de informática jurídica; y son habitualmente conocidas por los demás tribunales y la comunidad jurídica.

Luego, la labor de uniformación que se le asigna a la Corte probablemente se produzca por vías alternativas, no diseñadas (expresamente, al menos) para cumplir esa función, tal y como parece haber ocurrido hasta el día de hoy a propósito de la casación: por la vía de los mecanismos de calificación y disciplina de los tribunales cuyos fallos la Corte revisa. Ello es precisamente lo que incentiva la reunión de funciones políticas, administrativas, disciplinarias y jurisdiccionales en la cúspide del sistema judicial, puesto que ello incentiva a conformarse a los criterios del superior jerárquico por temor por la propia carrera, ascensos y consecuencias disciplinarias, más que por el mérito en derecho del caso concreto. En un contexto político en que el Poder Ejecutivo no vacila en entrometerse en la labor de la judicatura, dado que comprende a los jueces como instrumentos para implementar la política del ejecutivo $(v$.gr. la "lucha contra la delincuencia", la aprobación expedita de proyectos energéticos, etc.) y no como frenos 
Becerra - Corte Suprema y recurso extraordinario: algunas consideraciones...

institucionales al ejercicio del poder, ello resulta realmente complejo, pues, a su turno, la cabeza de la institucionalidad judicial tiene una agenda corporativa (autonomía financiera, entre otros puntos de dicha agenda) cuya satisfacción depende precisamente de aquellos a quienes los fallos de tribunales inferiores no les resultan agradables. Luego, el riesgo de impacto sobre la función judicial es notorio.

Ambos institutos -disciplina y calificación- confluyen en la misma cúspide de la pirámide judicial, que revisa las resoluciones impugnadas de quienes, al mismo tiempo, disciplina y califica; y que lo hace sobre la base de amplios espacios de discrecionalidad. Luego, la independencia interna del juez queda en entredicho si con ocasión del ejercicio de la función jurisdiccional puede arriesgar su carrera y futuro. Si ello ocurre, existe la posibilidad de que los criterios de adjudicación responden en todo o parte a razones funcionales para permanecer o promover la propia carrera, y los fundamentos de las decisiones ya no corresponderán a razonamientos jurídicos. Se genera una verdadera "uniformación por intimidación" frente a la perspectiva de arriesgar la carrera. Esto es nefasto, pues la función jurisdiccional se pierde, degenerando en una actividad sólo en apariencia jurisdiccional; y cada vez que ello ocurre, las personas y la sociedad son privadas de la justicia para la cual se instituyen los tribunales.

Este punto incide además sobre otro tema, en cuanto pone en evidencia los problemas de estructurar la judicatura nacional en torno a una "carrera judicial" que culmina en la Corte Suprema. En esencia, un juez preocupado por su carrera siempre verá comprometida su independencia interna frente a un órgano que puede decidir no sólo acerca de la revisión de su fallo, sino de su futuro en el poder judicial.

Se impone entonces la necesidad de repensar el sentido y rol de la Corte Suprema de cara al futuro. ¿Pero cómo ajustar una institución de origen monárquico pre republicano a las exigencias de una democracia moderna?

Para Juan Enrique Vargas, el gobierno judicial debiera mantenerse radicado en las Cortes Supremas, pero, al interior de estas, crearse entidades especializadas, dedicadas a las funciones de gobierno judicial. ${ }^{44}$ Por contrario, para Alberto Binder, la idea de gobierno judicial debe identificarse con la preservación de la independencia de cada uno de los jueces, por lo que disiente con Vargas, afirmando que "todo gobierno judicial debe estar radicalmente separado de las cortes supremas, ya que no existe ninguna razón para que un juez de los Tribunales Superiores ejerza el poder en nombre de los restantes miembros del

\footnotetext{
44 Vargas, Juan Enrique: “Gobierno Judicial: La Organización y el Rol de las Cortes Supremas", Sistemas Judiciales (CEJA) 10 (2006), disponible en:

http://issuu.com/sistemasjudiciales/docs/sistemas_10 [fecha de consulta: 3.10.12].
} 
poder judicial". ${ }^{45} \mathrm{Y}$ es que la carrera judicial y la selección de los miembros del tribunal no es un tema de mero gobierno judicial, sino que atañe a todo el sistema político. Bastante elocuente resulta al respecto el áspero debate público que genera la selección de los miembros de la Corte Suprema, que con un quórum constitucional de dos tercios de los miembros en ejercicio del Senado para la ratificación del candidato, tiende a replicar las dinámicas propias del sistema electoral binominal parlamentario.

Ambos autores proponen soluciones diversas para lo que es en esencia el mismo diagnóstico: que la función jurisdiccional debe estar separada de otro tipo de funciones. La reunión de estas funciones - juzgar, administrar y disciplinar- en un mismo ente genera culturas organizacionales e incentivos tremendamente perversos, que impactan negativamente sobre la independencia (interna) de cada juez y, con ello, sobre la idea misma de jurisdicción, puesto que el juez se verá expuesto a fallar el caso no conforme a sus propios méritos, sino como un vehículo para promover otro tipo de intereses; es decir, la falta de independencia interna promueve prácticas decisorias que no dependen de razones jurídicas.

$\mathrm{Y}$ es que, a ratos, pareciera que olvidamos que las instituciones son servidas por personas, individuos con anhelos, temores, defectos y virtudes. No sin una cuota de razón se quejaba Zaffaroni:

Si los operadores de un poder judicial verticalizado decidiesen un día dejar de practicar la maledicencia respecto de sus colegas, reinaría en los edificios de sus tribunales más silencio que en los templos. ${ }^{46}$

Esa dimensión no ha sido adecuadamente recogida en el diseño institucional de la Corte Suprema como cabeza de un Poder Judicial, y el desafío consiste entonces en visibilizar este problema y pensar cómo debiera diseñarse la Corte $-\mathrm{y}$ la estructura judicial en que se inserta- para anular o contrarrestar conductas o incentivos que impacten sobre la función jurisdiccional, esto es, sobre la capacidad de cada juez individualmente considerado para decidir el caso concreto en su propio mérito, sin consideraciones ajenas al mismo. Una posible alternativa encaminada a dicha finalidad -preservar la función jurisdiccional eliminando posibles incentivos internos- planteada hace varias décadas y que continúa teniendo adeptos hoy, ${ }^{47}$ consiste en la abolición de la carrera judicial como tal:

[...] En realidad, para garantizar la independencia del magistrado y salvarlo del conformismo, el remedio ideal, al cual se aproxima el

\footnotetext{
${ }^{45}$ Binder, Alberto M.: "Gobierno judicial y democratización de la justicia”, Sistemas Judiciales (CEJA) 10 (2006).

${ }^{46}$ Zaffaroni, Eugenio Raúl: Estructuras Judiciales, 1a ed., Ediar, Buenos Aires, 1994.

47 Atria, Fernando: "Jurisdicción e independencia judicial: el poder judicial como poder nulo", en Revista de Estudios de la Justicia No 5, 2005, pp. 119 y ss.
} 
Becerra - Corte Suprema y recurso extraordinario: algunas consideraciones...

sistema inglés, consiste en la abolición de los ascensos y el reconocimiento a todos los cargos judiciales, de cualquier grado, la misma dignidad y la misma remuneración, de manera que el magistrado, una vez nombrado en un cargo juicial con base a títulos técnicos, pudiese permanecer en él toda la vida, quamdiu bene se gesserit, libre del conformismo, hijo bastardo procreado por el matrimonio del temor con la esperanza. ${ }^{48}$

\subsection{Nulidad, recurso extraordinario, unificación de jurisprudencia. ¿'Teoría general del proceso?}

La forma insatisfactoria en que la Corte Suprema ha desempeñado su rol como tribunal de casación, en el contexto de un sistema que permanece en la indefinición acerca de qué debe y qué no debería hacer una Corte Suprema en un estado democrático de derecho, llevó a los redactores del NCPC a proponer la eliminación de la casación de nuestro sistema jurídico.

Ahora, aunque los redactores estaban en acuerdo acerca de la eliminación de la casación tal y como la conocemos, el recurso extraordinario no responde realmente a la visión de ninguno de los redactores, sino, al parecer, a una opción de compromiso. En particular, el profesor Tavolari era partidario de la eliminación del recurso de casación para reemplazarlo por una simple impugnación que permitiera a la Corte conocer de todas las cuestiones de hecho y de derecho comprendidas en el asunto debatido, y que le obligue a fundar debidamente sus resoluciones, sea al acoger el recurso, sea al denegarlo ${ }^{49}$. Junto a ello, proponía el establecimiento de un verdadero mecanismo de certiorari con el fin de que la Corte autodetermine su propia competencia, sabiendo de antemano los litigantes que su pretensión será revisada en un régimen de doble instancia, y sólo excepcionalmente por la Corte..$^{50}$

Ello obedece a que, en línea con las exigencias supranacionales sobre recursos y debido proceso, habría que simplificar no sólo la interposición de los recursos, sino las finalidades de fondo que a éstos se asignan. A lo que debe aspirarse es a que toda persona tenga, verdaderamente, derecho a "un recurso sencillo y rápido o a cualquier otro recurso efectivo ante los jueces o tribunales competentes, que la ampare contra actos que violen sus derechos...”, como preceptúa la Convención Interamericana. El agravio calificadísimo del recurso extraordinario, unido a los demás requisitos de admisibilidad, hacen del mismo un mecanismo de impugnación complejo, que se encuentra lejos de ajustarse, a nuestro juicio, de los parámetros de sencillez y efectividad sentados por la Convención; y su finalidad está igualmente lejos de la

\footnotetext{
${ }^{48}$ Calamandrei, op. cit., p. 87.

49 Tavolari, "Bases...", op. cit., p. 51.

${ }^{50}$ Ibid.
} 
REJ - Revista de Estudios de la Justicia - No 17 - Año 2012

búsqueda de la justicia -la función paradigmática de la jurisdicción- y más cercano a la función legislativa como hemos dicho antes.

A este panorama además se agregan interrogantes sistémicas que profundizan la dicotomía entre nuestro sistema nacional de impugnaciones y los parámetros interamericanos contemplados en la Convención.

La Corte Suprema ejerce jurisdicción no sólo en materia civil, desde luego, sino también en el contexto de un amplio catálogo de otras materias. De inmediato debe repararse en las competencias de la Corte Suprema en el contexto del proceso penal articulado en el Código Procesal Penal, que articula un régimen de impugnación especial, en los artículos 373 y 374 de dicho cuerpo normativo, que determinan las causales de procedencia del recurso de nulidad; y luego el 376 determina la competencia de la Corte Suprema en función de los supuestos que esa norma establece. Lo propio sucede en el Código del Trabajo que regula un particular recurso de Unificación de Jurisprudencia en los artículos 483 y siguientes, de competencia privativa de la Corte Suprema. En materia de familia, aunque el Código de Procedimiento Civil permanece como régimen supletorio, el artículo 67 de la Ley $\mathrm{N}^{0} 19.968$ introduce importantes modificaciones al régimen recursivo. Es decir, según la materia de que se trate, se articula un particular mecanismo de impugnación de resoluciones judiciales para ante la Corte Suprema.

Pero ¿qué justifica que para materias civiles deba acreditarse un "interés general" calificado (en términos del art. $409 \mathrm{NCPC}$ ) para llevar el tema a la Corte Suprema, mientras que para materias penales, la sola circunstancia de infringir sustancialmente derechos o garantías asegurados por la Constitución o por los tratados internacionales, o la existencia de divergencia jurisprudencial, habilita para acudir directamente a la Corte ${ }^{51} \mathrm{o}$, en materia laboral, basta acreditar que existen distintas interpretaciones sostenidas en uno o más fallos firmes emanados de Tribunales Superiores de Justicia? ? $^{52}$

¿Qué cosa, de haberla, caracteriza al derecho de familia en un modo tal, que justifica revisar las decisiones emitidas en dicho ámbito mediante una casación; y que, a la vez, lo diferencia del derecho laboral en un modo tal, que las decisiones en este último ámbito deban revisarse no a través de una casación, sino a través de un recurso de unificación de jurisprudencia?

¿Se condice con las exigencias de establecer un acceso sencillo y expedito a los tribunales esta multiplicidad de mecanismos de impugnación, que no parece tener otra justificación más que un desarrollo legislativo fragmentario $y$, a ratos, azaroso?

\footnotetext{
${ }^{51}$ Art. 376 inciso $1^{\circ}$ en relación con el art. 373 letra a), CPP.

52 Art. 483 Código del Trabajo.
} 
Becerra - Corte Suprema y recurso extraordinario: algunas consideraciones...

Este cuestionamiento, podrá advertirse, excede con creces de los solos mecanismos de impugnación a través de los cuales conoce la Corte Suprema, y puede predicarse respecto de todos los cuerpos normativos que articulan procedimientos. $\mathrm{Y}$ es que, realmente, si proceso civil y proceso de familia contemplan, digamos, una audiencia preparatoria, ¿cuál es el sentido de tener dos audiencias reguladas en forma separada, con diferencias menores, si la finalidad de la audiencia preparatoria en uno y otro caso es esencialmente la misma? No es que no existan particularidades en relación a la materia; es sólo que esas particularidades podrían satisfacerse con reglas igualmente específicas (i.e. contemplar la intervención de consejero técnico en materia de familia) adosadas a un diseño procedimental común. Existe entonces, a la luz del artículo 25 de la Convención, una necesidad de revisar esta multiplicidad de mecanismos de impugnación, y su compleja regulación, que no parece tener otra explicación más que la contingencia política.

Dicho de otro modo, no parece existir una justificación sustantiva para que en materia civil la Corte conozca a través de un complejo recurso extraordinario, mientras que en materia laboral lo haga a través de un recurso de unificación de jurisprudencia (similar pero bastante más laxo en sus requisitos de admisibilidad), en materia penal lo haga a través de un recurso de nulidad y en materia de familia a través de una casación. La revisión del régimen recursivo civil debiera ser ocasión para la revisión del régimen recursivo y de acceso general a la Corte Suprema, para establecer estándares análogos o, mejor aún, un mismo sistema de acceso a la Corte Suprema cualquiera sea la materia en que recae la decisión que se pretenda revisar.

\section{Conclusiones}

La reunión de funciones políticas, administrativas, disciplinarias y jurisdiccionales en una misma "cabeza" de un Poder Judicial -la Corte Suprema- acarrea problemas de gran consideración para un Estado Democrático de Derecho. La configuración escogida para un recurso extraordinario entregado a una Corte con dicho diseño genera más incertidumbres al respecto.

De particular notoriedad resulta el impacto adverso sobre la independencia de los jueces como resultado de que sus decisiones sean revisables por quien está llamado, al mismo tiempo, a calificarlos y decidir sobre su carrera: en tal configuración, el incentivo está puesto en conformarse a los criterios del superior jerárquico, más que en el mérito en derecho del caso concreto. En ese contexto, la relación de verticalidad entre distintos tribunales y jueces y el argumento de autoridad, propios de una estructura organizacional esencialmente monárquica y pre republicana, adquieren un protagonismo difícilmente compatible con la fundamentación de las decisiones de los órganos jurisdiccionales y la transparencia en el ejercicio de la función pública que exige la democracia. Así, la pretendida labor de uniformación que se asigna a la Corte a través del recurso extraordinario 
probablemente se produzca por vías alternativas, no diseñadas para cumplir esa función, es decir, a través de los mecanismos de calificación y disciplina de los tribunales cuyos fallos la Corte revisa. En un contexto político en que el Poder Ejecutivo no vacila en entrometerse en la labor de la judicatura, dado que comprende a los jueces como instrumentos para implementar la política del ejecutivo y no como frenos institucionales al ejercicio del poder, ello resulta realmente complejo, pues, a su turno, la cabeza de la institucionalidad judicial tiene una agenda corporativa (autonomía financiera, entre otros aspectos) cuya satisfacción depende precisamente de aquellos a quienes los fallos de los tribunales inferiores no les resultan agradables. Ello favorece lo que hemos denominado como "uniformación por intimidación": jueces preocupados de su carrera y cómo la forma en que deciden los casos agradará o no a quien está llamado a revisar sus decisiones y resolver sobre su futuro en el poder judicial.

El rol que se asigne a la Corte Suprema en el contexto de la Reforma Procesal Civil debe ser permanentemente evaluado bajo el prisma de qué constituye la mejor y más razonable configuración en función de la tutela de las garantías de las personas, entre ellas el derecho a ser juzgados por un juez independiente e imparcial. El recurso extraordinario tal y como se proyecta no parece ser una opción adecuada, pues lejos de estar concernido con la tutela de garantías fundamentales, se encomienda a la Corte velar por la consistencia o uniformidad en la jurisprudencia al afectarse un "interés general" calificado por el legislador, lo que es más cercano a una función de política pública o cuasilegislativa que a la función jurisdiccional, en la medida en que se encomienda a la Corte promover lo que estime el criterio correcto respecto de un problema jurídico, en nombre del interés general y con una finalidad esencialmente prospectiva. Una revisión profunda acerca de cómo impacta ello sobre el sistema constitucional de separación de poderes es requerida.

Además, la regulación del recurso extraordinario no sólo no soluciona, sino que probablemente exacerbará las tensiones institucionales entre la Corte Suprema y el Tribunal Constitucional, existiendo dos instituciones cuya misión central será hablar sobre el derecho de la Constitución en calidad de intérprete último, proveyendo de decisiones en base a ella y razonando sobre derechos fundamentales. Este es un punto del cual hay que hacerse cargo explícitamente, so riesgo de conflictos institucionales y criterios decisorios contradictorios, todo en perjuicio de la persona.

Las consideraciones expuestas sobre los cinco tópicos propuestos a discusión en este documento ponen en evidencia la inconveniencia de discutir el sistema recursivo escindido del diseño institucional del órgano a quien se asignan competencias en función de dicho régimen recursivo. El debate debiera asumirse en toda su complejidad, ya que el régimen recursivo es condicionado por el diseño institucional y culturas organizacionales de quien está llamado a administrarlo, y por las dinámicas institucionales en que se inserta quien está llamado a administrarlo. Tal y como se propone, el recurso extraordinario contribuiría a 
Becerra - Corte Suprema y recurso extraordinario: algunas consideraciones...

diluir la función jurisdiccional de la Corte, provocaría probables efectos adversos sobre la independencia interna de los jueces, generaría considerables conflictos con el Tribunal Constitucional, y, por sobre todo, no queda claro cómo es que contribuirá a una mejor justicia y tutela de derechos fundamentales para las personas, norte de toda actividad ya no sólo del sistema judicial, sino del Estado mismo.

La configuración de este recurso extraordinario -de cualquier recursodebe escogerse en función de los fines que, como opciones de política, defina la comunidad política, y esos fines deben manifestarse en los principales componentes estructurales del recurso: mecanismos de acceso al tribunal, resoluciones impugnables, incidencia del recurso sobre la resolución impugnada y el procedimiento en que se inserta, eficacia de las sentencias del tribunal, etcétera. La mirada desde los derechos fundamentales de la persona al momento de emprender reformas a nuestro sistema judicial es, entonces, insoslayable. 
REJ - Revista de Estudios de la Justicia - No 17 - Año 2012

\section{BIBLIOGRAFÍA}

* ALONSO GODOY, Pablo: “Corte Suprema: 179 años de historia”. Tesis, Universidad de Chile, 2000.

* ALVEAR, Soledad: “¿Quo Vadis Corte Suprema?” El Mostrador, 31 de julio de 2012, sec. Columnas:

http://www.elmostrador.cl/opinion/2012/07/31/quo-vadis-cortesuprema/\#disqus thread.

* ATRIA LEMAITRE, Fernando: “La Improbabilidad de la Jurisdicción”. Expansiva, 2007. http://www.expansiva.cl/publicaciones/en foco/detalle.tpl?iddocumento $=14112007100$ $\underline{957 .}$.

* AYLWIN AZÓCAR, Patricio: "Función de la Corte Suprema como tribunal de casación". Revista de Derecho Procesal (Universidad de Chile) 19 (1997).

* BINDER, Alberto M.: "Gobierno Judicial y Democratización de la Justicia". Sistemas Judiciales (CEJA) 10, 2006.

* BluCK, Nancy/ZAPATA, María Francisca/GAlLARDO, Eduardo/ GUZMÁN, Fernando: "Sobre propuesta Soledad Alvear en El Mostrador". Jurisdicción y Democracia, agosto de 2012,

- http://jurisdiccionydemocracia.cl/?s=Soledad+Alvear.

* BORDAlí SALAMANCA, Andrés: "Independencia y Responsabilidad de los Jueces." Revista de Derecho (Valdivia) 14, Julio 2003.

"Organización Judicial en el Derecho Chileno: un Poder Fragmentado." Revista Chilena de Derecho 36, No 2, 2009. http://www.scielo.cl/scielo.php?pid=S0718$34372009000200002 \&$ script $=$ sci arttext.

* BRAVO HURTADO, Pablo: "Unificación de jurisprudencia y recurso extraordinario en el proyecto de ley que establece un nuevo Código Procesal Civil”. Tesis, Universidad de Chile, 2011.

* BRAVO LIRA, Bernardino: Anales de la Judicatura chilena: durante cuatro siglos, por mí habla el Derecho. $1^{a}$ ed., Santiago, Corte Suprema de Chile, 2011.

* CAlamandrei, Piero: Proceso y Democracia, (Reimp.), ARA Editores, Perú, 2006.

* CAROCCA PÉREZ, Alex: "La Corte Suprema y sus Competencias en Chile. Reflexiones sobre las Funciones de la Corte Suprema." Ius et Praxis (U. de Talca) 1, 1998.

* Ceballos-escalera Y GIRA, Alfonso: "El Tribunal Supremo del Reino de España". Boletín Oficial del Estado, Madrid, 2008.

* CONNElLY, Thomas John: "La Reforma al Poder Judicial en Chile: La Designación de Magistrados del Poder Judicial y las Atribuciones o Facultades de la Corte Suprema". Biblioteca del Congreso Nacional, sin fecha.

* CONSEjO GENERAL DEL PODER JUDICIAL: El Tribunal Supremo en el Ordenamiento Constitucional. Jornadas en conmemoración del XXV Aniversario de la Constitución de 1978. $1^{\mathrm{a}} \mathrm{ed}$. Madrid, 2004.

* CUMBRE JUDICIAL IBEROAMERICANA: La Judicatura en Iberoamérica, sin fecha. http://www.cumbrejudicial.org/c/document library/get file?uuid=c62ae4fb-b43d-4c81bc38-7397017e7a1c\&groupId=10124.

* DE LA OLIVA SANTOS, Andrés: Casación, Oralidad y Nuevo Proceso Civil. Tres Conferencias Chilenas. Ediciones Jurídicas de Santiago, $1^{\text {a }}$ ed., Santiago, 2009.

* DELGADO CASTRO, Jordi: "La Historia de la Casación Civil Española: una experiencia que aconseja no avanzar en el modelo de unificación de la doctrina". Revista de Derecho (U. Católica de Valparaíso) 33, 2009.

* DELGado CASTRO, Jordi/DÍAZ GARCÍA, Iván: "La Unificación de Jurisprudencia Pretendida por el Recurso Extraordinario: ventajas y problemas". Revista de Derecho (U. Católica del Norte) 2, 2011. 
Becerra - Corte Suprema y recurso extraordinario: algunas consideraciones...

* DitTus CABRERA, Carla: "La función jurisdiccional de los tribunales supremos de justicia: determinación del rol de la Corte Suprema chilena bajo la propuesta de la reforma procesal civil". Tesis, Universidad de Chile, 2011.

* FlORES MONARDES, Álvaro: "Gobierno Judicial: el Caso Chileno. La Reforma Olvidada”. Revista de Estudios de la Justicia 6, 2005.

* ELGUETA ROSAS, María Francisca/PALMA GONZÁLEZ, Eric: La Investigación En Ciencias Sociales y Jurídicas, 2a ed. (revisada y actualizada), Santiago, Centro de Pedagogía Universitaria y Didáctica del Derecho, Facultad de Derecho, Universidad de Chile, 2010.

* GARCÍA, José Francisco: "Reforma al Poder Judicial: una Agenda para la Discusión". Libertad \& Desarrollo, Abril 2007.

http://www.lyd.com/wp-content/uploads/2011/11/SIP-100-Reforma-AL-PoderJudicial-Una-agenda-para-la-discusion-JFGarcia-Abril2007.pdf.

"Repensando el rol de la Corte Suprema en nuestro ordenamiento jurídico". Sistemas Judiciales (CEJA) 13, 2008.

* GARCÍA, José Francisco/CLARO, Eliana: "Reforma a la Justicia Civil y Comercial en Chile". Libertad \& Desarrollo, http://www.lyd.com/wp-content/files mf/sij9reformaalajusticiacivilycomercialenchileeclaroyjfgarciaabril2012.pdf.

- GONZÁLEZ MARTínEZ, María José: "La Corte Suprema en Chile: antecedentes y desarrollo en el siglo XIX”. Universidad Católica de Valparaíso, 2005.

* GUILHERME MARINONI, Luiz/PÉREZ RAGONE, Álvaro/NÚÑEZ OJEDA, Raúl: Fundamentos del Proceso Civil. Hacia una Teoría de la Adjudicación. Abeledo Perrot LegalPublishing, Santiago, 2010.

* LOZA, Laura: "Relación entre Gobierno Judicial y Administración de Justicia". en: Sistemas Judiciales, sin fecha,

- $\quad$ http://www.sistemasjudiciales.org/nota.mfw/137.

* NAvarro BELTRÁn, Enrique: "Notas sobre el Rol de la Corte Suprema en Chile". Expansiva, 2007,

- $\quad$ http://www.expansiva.cl/media/en foco/documentos/14112007103307.pdf.

* Nieva FENOLL, Jordi: El Recurso de Casación. Abeledo Perrot LegalPublishing, 1ªed., Santiago, 2010.

* NÚÑEZ OJEDA, Raúl: “Crónica sobre la Reforma del Sistema Procesal Civil Chileno (Fundamentos, Historia y Principios)". Revista de Estudios de la Justicia 6, 2005.

* ORTELLS RAMOS, Manuel: "El Tribunal Supremo Español: un tribunal en busca de identidad", sin fecha,

- http://derecho.procesal.unam.mx/cuadernos/pdf/tribunal.pdf.

* ORTElls RAMOS, Manuel (ed.): Los recursos ante Tribunales Supremos en Europa. Appeals to Supreme Courts in Europe. 1a ed., Difusión Jurídica y Temas de Actualidad, Madrid, 2008.

* PALMA GONZÁlEZ, Eric: Tareas Legislativas Del Poder Judicial: Aportes Para Un Debate Sobre Las Facultades Colegisladoras De La Corte Suprema, 1a ed. México: Suprema Corte de Justicia de la Nación, Dirección General de la Coordinación de Compilación y Sistematización de Tesis, 2010.

* Romero SEgUEL, Alejandro/AgUiRrEZABA LGRÜNSTEIN, Maite/BARAONA GONZÁLEZ, Jorge: "Revisión crítica de la causal fundante del recurso de casación en el fondo en materia civil". Ius et Praxis Año 14, N 1, 2008.

* ROSALES, Carlos M.: "La Administración del Poder Judicial a Través Del Consejo de la Judicatura", Revista de Estudios De La Justicia, Universidad de Chile 13, 2010.

* SALINAS QUERO, Celeste: "Nueva justicia constitucional: diálogo de competencias entre la Corte Suprema y el Tribunal Constitucional a la luz del recurso extraordinario del proyecto de ley para un nuevo código procesal civil’. Tesis, Universidad de Chile, 2010. 
REJ - Revista de Estudios de la Justicia - No 17 - Año 2012

* SILVA, José Pedro/GARCÍA, José Francisco/LETURIA, Francisco J. (eds.): Justicia Civil y Comercial: Una Reforma Pendiente. 1a ed. Libertad \& Desarrollo, Pontificia U. Católica de Chile, 2006.

* SQUELla NARDUCCI, Agustín: "Independencia interna del Poder Judicial: Ante quiénes, en qué y para qué tenemos jueces independientes". En La Judicatura como Organización, Expansiva, Instituto de Estudios Judiciales, Santiago, 2007.

* TAvolari Oliveros, Raúl: "Reflexiones sobre la Corte Suprema Chilena". En El Papel de los Tribunales Superiores. 1a ed., Rubinzal-Culzoni, Santa Fe, 2006.

Tribunales, Jurisdicción y Proceso. $1^{\text {a }}$ ed. Santiago, Editorial Jurídica de Chile, 2012.

* VALENZUELA SOMARRIVA, Eugenio/VERDUGO MARINKOVIC, Mario/CORREA AMUNÁTEGUI, Juan Ignacio/CORREA DE LA CERDA, Hernán/CEA EGAÑA, José Luis/PEÑA GONZÁLEZ, Carlos: Proposiciones para la reforma judicial. $1^{\text {a }}$ ed., Centro de Estudios Públicos, Santiago, 1991.

* VARGAS, Juan Enrique: "Alternativas para estructurar el gobierno judicial respetando la independencia de los jueces”. Expansiva, 2007.

- http://www.expansiva.cl/media/en foco/documentos/14112007102153.pdf.

* _ _Gobierno Judicial: La Organización y el Rol de las Cortes Supremas". Sistemas Judiciales (CEJA) 10, 2006.

* ZAFFARONI, Eugenio Raúl: Estructuras Judiciales. 1a ed., Ediar, Buenos Aires, 1994.

* ZAPATA, María Francisca: "Sin Temor ni Esperanza. Condiciones Estructurales de una Eficiente Juridificación de las Expectativas Normativas". Revista de Estudios de la Justicia, Universidad de Chile, 10, 2008. 